COP.AL, 1285

\title{
The Control of
}

TARTARY AUCKWHEAT

In

\section{A L B E R T A}

By G. R. STERLING

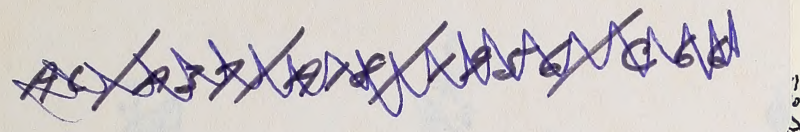
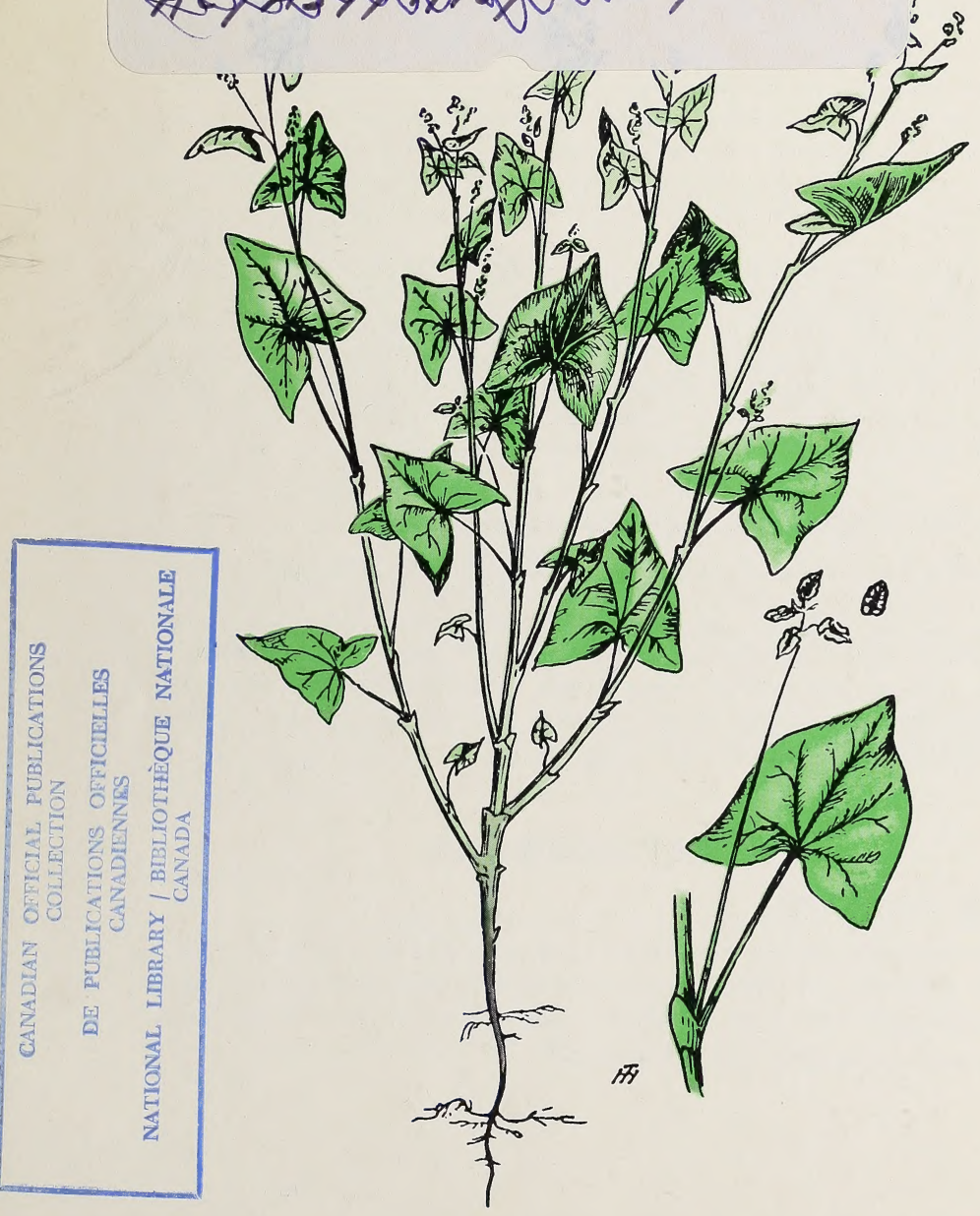


\section{TARTARY BUCKWHEAT}

(Fagopyrum tataricum)

Buckwheats are grown as commercial crops in many parts of the world including Eastern Canada. In these areas tartary buckwheat or rough buckwheat is often grown commercially and frequently is present as an impurity in other commercial buckwheats, but it does not create a weed menace. In many parts of Western Canada it is a serious weed. Under the Canada Seeds Act Tartary Buckwheat is named a prohibited Noxious weed in Western Canada and no grain that contains tartary buckwheat seeds may be sold as seed.

Tartary Buckwheat is an annual. It can be distinguished easily from wild buckwheat by its yellowish green colour and erect growth. Wild buckwheat is a twining vine with smooth black triangular seeds. The seed of tartary buckwheat is larger than wild buckwheat, it is greyish sand in color and roughly triangular in shape, with prominent crests at the centre of each angle. The faces of the seed are deeply grooved.

Seeds of tartary buckwheat in commercial grades of wheat darken the flour, and in malting barley they adversely affect the malt. Top arades of oats containing tartary buckwheat cannot be used for rolled or other processed products. The seeds of this weed are very difficult to separate from grain by ordinary cleaning processes, and as a result, grain is degraded if tartary buckwheat seeds are present.

\section{SPREADS FROM SEED}

The seeds of tartary buckwheat are oily and they must go through an after-ripening stage before they will grow. Even seeds from the same plant require different lengths of time to after-ripen. Soil of an infested field will contain dormant seeds, seeds ready to grow, and all in between stages. Seeds below three inches usually do not germinate until brought nearer the surface. The characteristics of delayed germination in tartary buckwheat is much the same as with wild oats.

\section{PREVENTION}

\section{SOW CLEAN SEED}

Be careful about the seed you use, and be particularly cautious if you are buying it from one who has tartary buckwheat on his farm. Spread your seed grain on white paper and check it carefully. Never use seed containing tartary buskwheat. 


\section{CHECK YOUR FIELDS}

Check fields early in the year, not only for tartary buckwheat plants but for other weeds too. Buckwheat usually shows up well against the short crop in the spring. Hand pulling of the first few scattered plants can well prevent infestation and save endless trouble in the future.

\section{CONTROL}

\section{CULTURAL METHODS}

There is no easy way to control tartary buckwheat. All cultivations should be shallow. Most seeds buried deeper than three inches fail to germinate but retain their viability. Deep plowing buries many seeds that will grow when worked to the surface in later years.

Killing at least one crop of tartary buckwheat before seeding the grain crop is good practice. Allow the plants to reach the three to five leaf stage between cultivations of summerfallow.

\section{SMOTHER CROP}

Late seeding of barley will allow time to kill at least one crop of tartary buckwheat before the barley is planted. If seeded heavily under fair growing conditions many weeds will be smothered. The effectiveness of the smother crop can be increased by application of fertilizer and by post seeding cultivation. The procedure would be as follows:

(I) Kill the buckwheat with shallow cultivation as soon as it reaches the 3 to 5 leaf stage.

(2) Allow about 8 days for other buckwheat seeds to germinate.

(3) Seed barley and a good application of fertilizer about 3 inches deep.

(4) Cultivate with a rod or cable weeder when the barley sprouts are $1 / 4$ to $1 / 2$ inch long.

The depth of cultivation should be above the barley sprouts; otherwise the rod weeding may also injure the barley. Check growth carefully because timing is important in this operation.

\section{FORAGE CROPS}

As mentioned earlier, seeds of tartary buckwheat will remain viable in the soil for several years. Forage crops, particularly if cut for hay, will thin down buckwheat infestations but cannot be expected to eradicate them. Cutting must be done before any buckwheat seed is formed. Usually at least two cuttings will be necessary. 
A light discing or other shallow cultivation in the spring of the 3rd and 4th year of the hay crop will tend to bring tartary buckwheat seeds to the surface where they will grow and can be cut with the hay. Don't break or cultivate the hay land deeper than three inches; otherwise seeds brought to the surface will again infest the crop.

\section{CHEMICAL CONTROL}

Tartary buckwheat plants are somewhat resistant to 2,4-D. The resistance increases as the plants mature. Reasonable control can often be obtained if the 2,4-D is applied when the plants are small. Better results will be obtained if growing conditions are good. Low volatile esters have proved slightly better than other forms of 2,4-D.

Apply the 2,4-D as heavily and as early as the crop will tolerate. If post seeding cultivation has been properly done the crop will be ahead of the buckwheat. The rate should be 6 to $8 \mathrm{oz}$. acid equivalent per acre depending on the cereal crop.

\section{GDDD FARMING}

To eradicate tartary buckwheat, adopt good farming practices. Use a complete crop rotation and grow good crops while destroying the weed.

1. Sow perennial forage and leave it down for at least three years.

2. When the sod is established, cultivate lightly in the spring to grow out the buckwheat seeds.

3. Avoid deep plowing or cultivation when sod is broken.

4. Seed barley late with a good application of fertilizer.

5. Post cultivate when barley sprouts are $1 / 4$ to $1 / 2$ inch long.

6. Kill any remaining plants with 2,4-D.

Prepared by

FIELD CROPS BRANCH

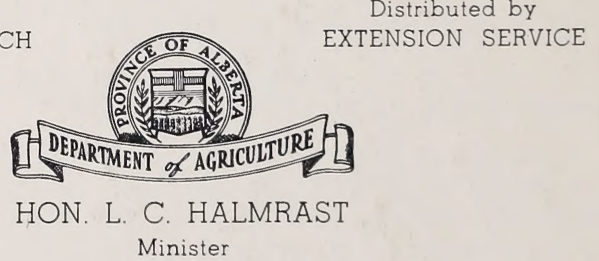

For additional information and bulletins SEE YOUR DISTRICT AGRICULTURIST 